essays focused on skiing, Glenbow Museum founder Eric Harvie, the conservation of historic places in Saskatchewan and the links between historian W. L. Morton and Margaret Laurence.

This collection pulls together nicely. It makes no pretense of providing a coherent history of the west - if that is even possible - but rather a series of thematically linked snapshots, or perspectives as the title suggests, of the region. Struggling against a relentless historiography stretching over decades that focused on settlement and governance, the collection has little to say about the details of both though much to say about their implications and ramifications. As the editors intended, The West and Beyond, is most useful as a book that challenges us to perceive the west as both a region that is constantly being reimagined and one enmeshed with a broader world. In that sense, with a nod to the book's cover, which features a gravel road stretching across an endless prairie, The West and Beyond is an intellectual starting point, rather than an end.

Dale Barbour

University of Toronto

\title{
Peter Morton Coan, Toward a Better Life: America's New Immigrants in Their Own Words-From Ellis Island to the Present (New York: Prometheus Books, 2011).
}

The human experience of migration lies at the center of this work: "sometimes sad or angry, other times joyous, tragic or bittersweet ..." (36). The collection of interviews includes fifteen-year-old Ava Rado-Harte's late-night escape to Austria during the 1956 Hungarian Revolution, the well known von Trapp family's story portrayed in the Sound of Music, and the illegal entry and fairy tale success of Cesar Millan, the "Dog Whisperer." Coan notes: "few subjects remain as controversial and emotionally charged -- and central to being American -- as immigration," (25).. He identifies continuing themes in the immigrant experience -- discrimination, immigration as a filtering process -- but also identifies differences in countries of origin, policy and process changes, and technological advances. "The world has changed. The game has changed. Immigration has changed." (29)

"The very things they said about the Irish, Italians, eastern Europeans and the Jews coming in," Coan quotes one immigration scholar, "are word for word the same accusations being leveled against Hispanic and Asian immigrants coming in today." (25) Coan correctly notes continued tensions and an immigration policy, "geared to reject people rather than to accept them . . . to separate 
the wheat from the chaff ...." (25). He also traces the evolution of the process of immigration. For example, the transfer of responsibility for alien processing to US consulates or embassies in the 1930s eliminated the need for Ellis Island, and the current complexity of rules that would have left the majority of American's ancestors "on the docks because they wouldn't have been able to get on the boat." (32)

No longer mostly from Europe, most immigrants hail from Asia, Africa, or South America. They too seek a better life, but "many of them today are more educated and offer more in the way of professional knowledge in science and technology, fields that have made coming to America easier for all immigrants." During the Ellis Island era, "Going to America ... was almost like going to the moon." Instead of a month long travel, today's immigrants travel in less than a day. "Much of the fear of the unknown is less today - new immigrants can click on the Internet and see exactly where they are going." (29)

While these interviews are compelling, there are significant organisational and perceptual problems that do not frame them properly. Coan defined the most representative and "best" stories as those "where the emotion was the strongest [and] tended to be the most accurate and telling." (37) Emotion serves to grip the reader, however it may also sway the accuracy of the stories and not provide a representative sample. Coan maintains that "each decade has experienced a different immigration profile, and so migration flows are researched on a decade-by-decade basis." (37) Organising by decades may provide an appealing order, but it ignores the significance of major pieces of immigration policy that actually drove the immigrant profile.

Structuring the parts of the book around the opening to closing of Ellis Island (Part I 1892-1954) and (Part II until 2010) creates other problems. Coan accurately claims that "to best understand America's new immigrants, one must first understand America's old ones," (36) however he fails to provide any historical context to those that came before Ellis Island opened. Coan maintains that with the most recent economic recession "new immigrants, for the first time, have begun to question whether coming here is still the answer" (31) yet neglects the 1890s and 1930s depressions when immigrants asked similar questions.

Finally, Coan asserts that "during the Ellis Island era, the drivers of freedom were numerous: political, social, legal, medical, educational, economic, religious, and more. Today, in this modern era of tolerance, economic freedom is by far the principal motivation of immigrants ..." (27-28). This implies that economics played a lesser role for earlier immigrants and downplays other fac- 
tors across periods. Coan claims a current "era of tolerance," a stand many would contest, particularly concerning immigration.

"It's been a wonderful life," reported Faye Lundsky who at five years of age emigrated from Russia with her mother in 1898. At the same age in 1991, Marie Gonzalez came from Costa Rica with her family. "I love this country," she stated in Congressional testimony. From escaping the pogroms in Russia to enduring the rollercoaster ride of passage of the proposed DREAM Act, these stories chronicle "ordinary people who will go to extraordinary lengths in their quest for freedom . . . for a taste of what many of us take for granted." (25) Peter Morton Coan wisely lets the immigrants tell their stories in their own words and, despite some organisational and perceptual challenges, provides an outstanding collection of immigrant stories.

John Bieter

Boise State University

\section{Axel Körner, Politics of Culture in Liberal Italy: From Unification to Fascism (New York: Routledge, 2009).}

One might approach Politics of Culture in Liberal Italy with the logical assumption that it is, as the title suggests, an analysis of the development of a political and cultural identity in Italy from the end of the Risorgimento to the first years of Fascism. However, while Körner states that "this book is concerned with the relationship between cities and the nation, and the attitudes of those cities towards modernity, as articulated through municipal cultural policy" (3), much of the work is a close assessment of the formation of cultural and politics in one city, Bologna, which Körner considers paradigmatic of the rest of the nation. Even if he justifies his choice to perform a case study of Bologna as a means with which to understand "l'Italia delle cento citta" (5) in the introduction, the title is misleading in two ways: besides the geographical issue, there is the cultural one, since the majority of Körner's analysis of culture focuses on musical performance and, to a lesser extent, architecture, largely neglecting other major spheres of intellectual and artistic output. The result is useful for our understanding of specific aspects of the culture of liberal Italy, but does not provide a complete overview of the characteristics of the period or issues named in the title.

Because of the great number of topics covered, the volume does not lend itself to an exhaustive summary. I therefore limit the following to some chief points. After the introduction, the book is divided into three parts: "Political and Social Conflict," "Writing the Past," and "The City, the Nation and 